\title{
COMPOSIÇÃO E ABUNDÂNCIA DO LIXO MARINHO NO MESO E SUPRALITORAL DE PRAIAS DO SUL DA BAHIA
}

\author{
AUTOR: MILENA COSTA LOPES \\ CO-AUTOR/ORIENTADOR: LEONARDO EVANGELISTA MORAES
}

\begin{abstract}
Resumo: Os resíduos sólidos antropogênicos (RSA) acarretam inúmeros problemas ambientais que atingem os ecossistemas marinhos, com impactos inclusive na saúde das pessoas que se inserem ou se utilizam destes ambientes. Com a alta demanda populacional e a crescente procura por praticidade, os descartáveis plásticos moldaram os padrões de produção e consumo de vários itens que atendem as demandas humanas. Sendo um derivado do petróleo, o plástico tende a ter um tempo vida útil prolongado na natureza. Assim, a combinação de grande produção e tempo de vida fazem com que os plásticos sejam o principal RSA responsável pela poluição de diversos ambientes terrestres e marinhos. . Sua entrada no ambiente marinho deriva de diversos meios, a exemplo das correntes marítimas que trazem para a costa o que chamamos de "lixo internacional", das atividades domésticas e de pesca que geram o "lixo doméstico" e o "lixo de pesca". Em todos os casos, as formas inapropriadas de descarte do lixo e a falta de gestão de resíduos sólidos agravam a poluição gerada pelo lixo marinho. Neste trabalho, buscamos caracterizar a composição, bem como identificar a distribuição e abundância do lixo marinho em áreas do supralitoral e mesolitoral de praias do extremo Sul da Bahia. Para tanto, os dados tabelados até então apontam a algo que já é de se imaginar em referência a qual categoria mais se destaca dentre a vasta listagem de itens, que seria a do plástico.
\end{abstract}

Palavras-chave: Lixo marinho, resíduos sólidos antropogênicos (RSA), poluição. 